\title{
Una mirada a la Tierra. Valoración del patrimonio paleontológico
}

Francisco Giles Pacheco | arqueólogo y ex-Director del Museo Municipal de El Puerto de Santa María Esperanza Mata Almonte | arqueóloga

URL de la contribución <www.iaph.es/revistaph/index.php/revistaph/article/view/4174>

Nuestra participación en este foro de debate sobre el patrimonio paleontológico siendo arqueólogos obedece a un interés por sumarnos a la reivindicación de su relevancia y de clarificación de su marco jurídico de protección. Nuestra reflexión parte, por un lado, de nuestra experiencia profesional en el marco de la prehistoria, donde hay un trabajo común de ambas disciplinas; $y$, por otro, de nuestra trayectoria en la defensa y protección del patrimonio arqueológico.

La denominación de "patrimonio" ya indica que le reconocemos valores y significado relevante para el desarrollo de la sociedad. Al nombrar el adjetivo se marcan las diferencias, se visibiliza su singularidad y se concretan objetivos e intereses: arqueológico, etnográfico, industrial, paleontológico, inmaterial... Aunque a veces las diferencias no son tan nítidas. La propia evolución del concepto de patrimonio permite hoy una visión integral del mismo, así se vincula patrimonio cultural y natural. Y, desde ambas perspectivas, se puede enfocar la protección de los bienes paleontológicos, pero creemos que en su conjunto, evitando que al final se creen diferencias normativas entre paleontología "prehistórica" y paleontología "histórica" (vinculada a la presencia humana). En las leyes autonómicas, de redacciones muy variadas, suele prevalecer el tratamiento desde el punto de vista del patrimonio cultural y la arqueología.

Desde esta visión "cultural", la misma Ley de Patrimonio Histórico de Andalucía 14/2007 menciona ya los "valores paisajísticos y ambientales". En el patrimonio inmueble cita, dentro de la clasificación de los bienes de interés cultural, en el artículo 26.5, las zonas arqueológicas, incluyendo los restos "paleontológicos de interés relevante relacionados con la Historia de la Humanidad". Podríamos pensar que al incluir en el art. 47 , en el con- cepto de patrimonio arqueológico, que "...forman parte de este patrimonio los elementos geológicos y paleontológicos relacionados con la historia de la humanidad y sus orígenes y antecedentes", existe ya el marco jurídico. Pero sabemos, desde la arqueología, que la interpretación de la normativa deriva en ocasiones a criterios individuales y gestiones dispares de "lo que quiere decir". En el desarrollo posterior del articulado de la ley prevalece solamente la mención "arqueológica". En general, se inserta mejor en esta normativa los "bienes inmuebles paleontológicos" (que se relacionan, por ejemplo, para las ocupaciones humanas, con captación de recursos, caracterización paleogeográfica del asentamiento...) que los "bienes muebles paleontológicos", de protección menos clara, sobre todo para los períodos geológicos sin presencia humana. Prima la conceptuación antrópica del yacimiento en los casos, por ejemplo, de los yacimientos paleontológicos de la depresión de Guadix-Baza, en Granada; Fonelas P-1 es un yacimiento paleontológico de edad Plioceno-Pleistoceno, situado en la localidad granadina de Fonelas (España). Está declarado como lugar de interés geológico español de relevancia internacional (Geosite) por el Instituto Geológico y Minero de España, con la denominación "VP014: Fonelas P-1", dentro de la categoría yacimientos de vertebrados del Plioceno-Pleistoceno español.

Podemos pensar que dicha ley puede ser hoy la fórmula más rápida para otorgarle al patrimonio paleontológico una protección dentro de un marco normativo ya existente sobre patrimonio histórico. El carácter de fragilidad de los bienes o el impacto de las actividades antrópicas actuales sobre el territorio son aspectos comunes al patrimonio arqueológico y paleontológico. Conceptos como el contexto o los bienes muebles y bienes inmuebles son aplicables en ambas disciplinas. En la reglamen- 
a debate El marco legal para la protección del patrimonio paleontológico. ¿Qué pasa en tu comunidad?

tación de las actividades arqueológicas hay establecido la regulación de los proyectos, procedimiento de autorizaciones, cautelas de intervención, coordinación con planes urbanísticos o figuras de protección, como bien de interés, que podrían aplicarse al patrimonio paleontológico y a la tramitación de actividades paleontológicas. Asimismo, existe regulación sobre la redacción de memorias, un canal de publicación (anuarios) y depósitos de materiales en museos que creemos interesante como armazón para aplicar al patrimonio paleontológico. Aunque esta normativa no está exenta de continuas reivindicaciones de su modificación por parte de los colectivos de arqueólogos.

Esbozamos en este debate el tema sobre la profesionalización: desde la arqueología vivimos una evolución de la profesión, de ámbitos públicos a ámbitos privados, no exenta hoy de discrepancias y continuas reivindicaciones. La valorización de la profesión no es ajena a debates de orden interno o en la relación con otras disciplinas. Creemos que, los paleontólogos, como profesionales, tienen una vinculación más estrecha con el ámbito público, universidades o centros de investigación. En este armazón normativo, la presencia de técnicos de distintas disciplinas, según el objeto de la intervención, genera menos dudas en los proyectos generales de investigación pero difiere en actividades preventivas. Por ejemplo, ¿qué papel tiene hoy en Andalucía el paleontólogo en estas prevenciones? Por otro lado, creemos interesante evaluar el grado de conocimiento del patrimonio paleontológico en la comunidad andaluza a nivel de catálogos actualizados y un análisis de la normativa, de autonómica a municipal, para trabajar sobre qué está siendo protegido y qué no. Una base de este conocimiento para su gestión, en el caso del patrimonio arqueológico, fueron las cartas arqueológicas. Traemos el ejemplo de la comunidad de Murcia, que puso en marcha, ya en 1998, un Plan de Estructuración de la Protección del Patrimonio Paleontológico Regional, con objetivos como definir necesidades de la regulación normativa, catálogo de yacimientos y colecciones, evaluación de riesgos, etc. Parte de este conocimiento ha sido incorporado al Inventario Andaluz de Georrecursos

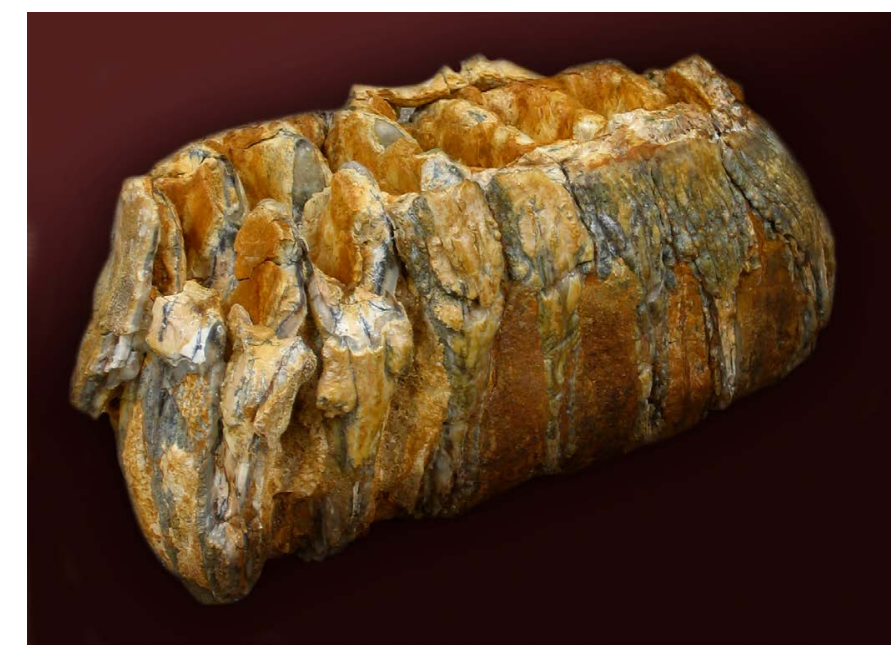

Molar de Mammuthus meridionalis (Nesti, 1825) procedente del yacimiento de La Florida (El Puerto de Santa María, Plio-Pleistoceno | foto Museo municipal del Puerto de Santa María (Cádiz)

Culturales, elaborado desde la visión "natural", con un interés en destacar los valores científicos, didácticos o turísticos e incluyendo categorías de componente "cultural", como la geominera o geoarqueológica. En realidad, actualmente existe una excesiva multiplicación de nomenclaturas, quizás fuera necesario un esfuerzo por aunar conceptos que sólo podría resultar de una interdisciplinariedad real en la investigación y gestión del patrimonio. Recientemente, en la edición de un estudio multidisciplinar del yacimiento de la Era Cenozoica del El Manantial en el Puerto de Santa María (Cádiz), centrado principalmente con las colecciones de fósiles pertenecientes a los fondos del Museo Municipal de esta localidad, se presenta una interesante propuesta para su gestión patrimonial tomando como modelo los yacimientos paleontológicos del Manantial- Base Naval-El Puerto de Santa Ma-Rota, que según su coautor (RUIZ GIL, 2017) servirá como premisa para la propuesta de su "definición patrimonial" en el contexto de "yacimiento paleontologico" anterior a la presencia humana. Creemos que es de interés señalar brevemente en este debate intervenciones "pioneras" en yacimientos paleontológicos pre-Cuaternarios en Andalucía, descubiertos como consecuencia de aperturas de explotaciones de áridos que dio lugar a hallazgos de restos fósiles de vertebrados 
a debate El marco legal para la protección del patrimonio paleontológico. ¿Qué pasa en tu comunidad?

del Plio-Pleistoceno en el año 1985 y que fueros depositados en el Museo Arqueológico Municipal del Puerto de Santa María. Su gran importancia derivó a su catalogación con propuestas de intervenciones como zona de interés paleontológico en la provincia de Cádiz, realizándose excavaciones sistemáticas de un yacimiento con fósiles de proboscídeos Anancus y Mammuthus. Paralelamente en esta misma época, 1985, se redactó un inventario con referencia a más de una veintena de enclaves paleontológicos actualizando nuevas fichas técnicas de información, equivalente al modelo de catalogación similar a las cartas arqueológicas, propuesta por la Dirección General de Bienes Culturales de la Consejería de Cultura de la Junta de Andalucía.

\section{BIBLIOGRAFÍA}

- LÓPEZ AMADOR, J. J. (coord.) (2017) Paleontología en el Manantial. La bahía de Cádiz hace millones de años. Cádiz: Universidad, Servicio de Publicaciones, 2017 (Monografías Ciencias Naturales)

- MANClOVA BOHÓRQUEZ, A.; GILES PACHECO, F. (1987) Informe Preliminar (1985) sobre las excavaciones de La Florida (El Puerto de Santa María, Cádiz): Geomorfología, Paleontología, Prehistoria. En Anuario Arqueológico de Andalucía/1985, Il Actividades Sistemáticas. Sevilla: Junta de Andalucía, Consejería de Cultura, 1987, pp. 199-206

- ROMERO SÁNCHEZ G. (2005) La protección del patrimonio paleontológico en la región de Murcia: experiencias e iniciativas. De Re Metallica, 5, 2005, pp. 21-30

- RUIZ GIL, J. A. (2017) Los yacimientos paleontológicos de El Manantial-Base Naval (El Puerto de Santa María-Rota, Cádiz) Propuestas para su gestión patrimonial. En LÓPEZ AMADOR, J. J. (coord.) Paleontología en el Manantial. La bahía de Cádiz hace millones de años. Cádiz: Universidad, Servicio de Publicaciones, 2017 (Monografías Ciencias Naturales), pp. 133-138 